\title{
Do sexual expectancies and inhibitions predict high-risk sexual behaviours? Evidence from a cross-sectional survey among young psychoactive substance users in informal settlements in Kampala, Uganda
}

Tonny Ssekamatte ${ }^{1 *}\left(\mathbb{D}\right.$, Simon P. S. Kibira², Moses Tetui ${ }^{3,4,5}$, John Bosco Isunju', Richard K. Mugambe', Solomon Tsebeni Wafula ${ }^{1}$, Esther Buregyeya ${ }^{1}$, Christine Kayemba Nalwadda ${ }^{2}$, Justine Nnakate Bukenya ${ }^{2}$ and Rhoda K. Wanyenze ${ }^{1}$

\begin{abstract}
Background: Psychoactive substance use is a public health challenge among young people in informal settlements. Though rarely examined, psychoactive substance use is linked to sexual expectancies and inhibitions, and consequently high-risk sexual behaviours. This study examined the association between sexual expectancies and inhibitions, and high-risk sexual behaviours among young psychoactive substance users (PSUs) in informal settlements in Kampala, Uganda.
\end{abstract}

Methods: This cross-sectional study recruited 744 young PSUs from informal settlements in Kampala. Respondent driven sampling was used to recruit respondents. A 'modified' Poisson regression model was used for inferential statistics. Data were analysed using the Stata 14 software.

Results: Of the 744 study participants, $45.6 \%$ believed that psychoactive substance use improves sexual performance; $43.3 \%$ believed that psychoactive substances make sex more pleasurable, and $53.3 \%$ believed that psychoactive substances give courage or confidence to approach a partner for sex. The belief that psychoactive substance use improves sexual performance (PR 1.14,95\% Cl: 1.01-1.30), increases the likelihood of engaging in sex (PR 1.20, 95\% Cl: 1.04-1.40) or gives courage or confidence to approach a sexual partner (PR 1.21,95\% Cl: 1.05-1.39) were associated with having sex while under the influence of psychoactive substances. The belief that a psychoactive substance user under the influence of psychoactive substances is more likely to engage in sex (PR 1.48, 95\% Cl: 1.15-1.90), and likely to find it difficult to refuse sex (PR 1.28, 95\% Cl: 1.06-1.55) were positively associated with engaging in multiple sexual partnerships. The belief that one easily forgets to use a condom when

* Correspondence: ssekamattet.toca@gmail.com; tssekamatte@musph.ac.ug

${ }^{1}$ Department of Disease Control and Environmental Health, Makerere

University School of Public Health, Kampala, Uganda

Full list of author information is available at the end of the article

(c) The Author(s). 2021 Open Access This article is licensed under a Creative Commons Attribution 4.0 International License, which permits use, sharing, adaptation, distribution and reproduction in any medium or format, as long as you give appropriate credit to the original author(s) and the source, provide a link to the Creative Commons licence, and indicate if changes were made. The images or other third party material in this article are included in the article's Creative Commons licence, unless indicated otherwise in a credit line to the material. If material is not included in the article's Creative Commons licence and your intended use is not permitted by statutory regulation or exceeds the permitted use, you will need to obtain permission directly from the copyright holder. To view a copy of this licence, visit http://creativecommons.org/licenses/by/4.0/. The Creative Commons Public Domain Dedication waiver (http://creativecommons.org/publicdomain/zero/1.0/) applies to the data made available in this article, unless otherwise stated in a credit line to the data. 
under the influence of psychoactive substances was positively associated with inconsistent condom use (PR 1.26, 95\% Cl: 1.09-1.45).

Conclusion: Psychoactive substance use expectancies associated with high-risk sexual behaviours included the belief that psychoactive substances improve sexual performance and improve confidence in approaching a sexual partner. Psychoactive substance use inhibitions associated with high-risk sexual behaviours included an increased likelihood of engaging in sexual intercourse, difficulties in refusing to engage in sexual intercourse, and forgetting to use condoms while intoxicated. Interventions targeting a reduction in high-risk sexual behaviour should integrate the impact of psychoactive substance use on sexual behaviour.

Keywords: High-risk sexual behaviours, Young people, Informal settlements, Sexual expectancies, Psychoactive substance

\section{Background}

Globally, more than a quarter of a billion people use psychoactive substances such as khat, marijuana, heroin and alcohol [1]. According to the 2020 World drug report, over 192 million people used cannabis, 58 million used opioids, 27 million used amphetamines and prescription stimulants and 19 million used cocaine [1]. The use of psychoactive substances increased at a faster rate in developing countries and was high among adolescents and young adults [1]. Data on the burden of psychoactive substance use among young people in Uganda remains scarce. However, a school survey conducted in Gulu and Kampala cities indicated that $70.1 \%$ of secondary school youths had ever used a psychoactive substance, while $39.1 \%$ were regular users of psychoactive substances [2]. The survey indicated that $20.6 \%$ of the secondary school youths in Kampala had ever used alcohol, 8.0\% had ever used marijuana (Cannabis sativa), 9.9\% had ever used oral tobacco (locally known as kuba), 9.7\% had ever used khat (Catha edulis), and 9.9\% had ever used aviation fuel [2]. However, the use of psychoactive substances is likely to be higher in the informal settlements due to vulnerabilities such as unemployment and poor parenting [3].

Informal settlements, defined as residences in urban areas that are characterised by limited access to social services, including those related to access to healthcare, are known to have a high prevalence of psychoactive substance use $[4,5]$, especially among young people $[6$, 7]. The high prevalence of psychoactive substance use that characterises informal settlements [6], is a predictor of high-risk sexual behaviours such as multiple sexual partnerships and unprotected sexual intercourse [8-11]. As a result, informal settlements like those in Kampala have high rates of sexually transmitted infections, including HIV [12].

The relationship between psychoactive substance use and high-risk sexual behaviours has been widely studied. Nevertheless, understanding the theoretical basis of this relationship is vital. The theoretical point of departure in this study is enshrined in the theories of alcohol myopia, cognitive escape, and expectancy. These theories provide the basis for discussions on how the use of psychoactive substances influences users' perceptions and actions [13, 14]. Users of psychoactive substances often hold beliefs of various perceived benefits from these substances. According to the expectancy theory, users assume that psychoactive substances will reduce sexual inhibitions, such as lack of confidence in approaching sexual partners, and enhance benefits such as sexual pleasure, arousal, and performance [15-18]. Such expectancies often drive the desire to engage in high-risk sexual behaviours. Generally, a reduction in sexual inhibition and an increase in expected sexual benefits makes sexual life among users riskier [15].

Users of psychoactive substances associate them with increasing sexual arousal, delaying premature ejaculation, and prolonging sexual intercourse [16]. Such perceptions are often driven by cultural beliefs that portray good sex as long and penetrative [16]. In a society where having a sexual partner is necessary to show that someone is normal, the use of psychoactive substances has been key in stimulating erections and boosting the confidence of young people to initiate sexual relationships or engage in sexual intercourse [16].

High-risk sexual behaviours can be viewed from the perspective of impaired cognition, which can be explained by the alcohol myopia and cognitive escape theories. Based on the cognitive escape theory, individuals may opt to use certain substances to escape the selfknown implications of high-risk sexual behaviours [19]. Similarly, the alcohol myopia theory points out that the use of psychoactive substances such as alcohol often alters perceptions, mood and decision making [13, 20]. Therefore, psychoactive substances are often used to disengage mental processes related to the prevention of negative consequences of high-risk sexual behaviour [20, 21]. Cognitive escape is often driven by expectancies 
such as better sexual pleasure and performance and is associated with turning attention away from threatening cues [22]. However, these sexual expectancies are shortlived, while the consequences of engaging in high-risk sexual behaviours pose long-term negative effects [19, 22, 23].

There is an emerging body of evidence suggesting an interaction between sexual expectancies, inhibition, and escape from self-awareness of HIV/AIDS risk and highrisk sexual behaviours, especially among men who have sex with men [21], and young people in high-income countries $[24,25]$. Young people in peri-urban settings often have a higher tendency to take risks and engage in high-risk sexual encounters [26-28]. Peri-urban settings in Africa generally have a growing challenge of psychoactive substance use [29-32], but relatively less research has been conducted in these settings. Some studies also show that the use of some of the drugs such as heroin and alcohol which are viewed as less risky on the other hand often lead to injecting drug use [33-35], which is more difficult and expensive to manage [36].

The mechanisms underlying the association between psychoactive substance use and high risk sexual behaviours have been extensively examined [37]. However, there is a dearth of evidence linking psychoactivesubstance use related expectancies and inhibitions, and self-reported high-risk sexual behaviours [38]. In this study, we hypothesised that sexual expectancies such as improved sexual pleasure and performance, and inhibitions are associated with high-risk sexual behaviours such as engaging in multiple sexual partnerships or relationships, inconsistent condom use, and sexual intercourse, while under the influence of psychoactive substances. Kampala Capital City was chosen as the ideal study site because of its representativeness of cities in the global south [39]. In addition, the informal settlements of Kampala are characterised by a high prevalence of psychoactive substance use and high-risk sexual behaviours among young people [40-43]. Findings of this study provide insights for targeting sexual and reproductive health interventions that aim to reduce sexually transmitted infections among young PSU in informal settlements.

\section{Methods}

\section{Study design, setting and population}

This was an analytical cross-sectional survey conducted between June and July 2019 among young psychoactive substance users in 12 out of the 57 informal settlements in Kampala city, Uganda. We defined an informal settlement as an urban residence characterised by inadequate access to social services and poor structural quality of housing, overcrowding and insecure residential status [44]. Such settlements are characterised by a high prevalence of psychoactive substance use [45-47] and high- risk sexual behaviours [42]. The study was conducted in four of the five divisions of Kampala (including Kawempe, Makindye, Lubaga, and Nakawa). Kampala has an estimated population of over 1.5 million people, $70 \%$ of whom (live in informal settlements [48]. Kampala is Uganda's main economic hub, generating $65 \%$ of the national Gross domestic product (GDP).

The study participants included sexually active young people aged between 18 and 24 years who had a recent history of using at least one or more psychoactive substances, and had resided within the informal settlements of Kampala city for at least 6 months. The most commonly used and accessible psychoactive substances of interest in these settings were alcohol, khat, oral tobacco, marijuana, and heroin. The age group of 18-24 years was considered because it is a critical risk period for the initiation of substance use $[1,49]$. We excluded non-residents (e.g., visiting relatives or friends), and those who were not mentally sound or intoxicated during the survey. We trained research assistants to be sensitive to behavioural signs of intoxication such as loss of co-ordination, staggering gait, drowsiness, slurred speech and glazed eyes for alcohol users, and paranoia, anxiety, eye-rolling, pupil dilation/constriction, head movements or jerks for other substances [50]. Research assistants were cautioned to remind the participants of their right to withdraw, particularly when observable signs of intoxication appeared to change [50].

\section{Sample size}

A total of 768 young PSUs were estimated as the appropriate sample size for this survey using the Kish Leslie formula for cross-sectional studies [51]. We assumed a prevalence of high- risk sexual behaviours among young PSUs of $50 \%$ because of the limited literature in the study domain. We assumed a 5\% margin of error for the estimated prevalence, 95\% confidence interval around the estimates, and a design effect of 2.0 to adjust for clustering by informal settlement [52]. A design effect of 2.0 is recommended for behavioural surveys that use respondent driven sampling (RDS) [53]. A final sample of 744 young PSUs was interviewed.

\section{Sampling}

The detailed sampling procedure for the current study has previously been reported [54]. Briefly, we purposively selected 12 informal settlements (four in Nakawa, four in Kawempe, two in Lubaga, and two in Makindye) and these were selected with the aim of geographical representativeness of informal settlements [54]. Respondent-driven sampling was used in the selection of study participants, since it is recommended for hard-to-reach populations such as young psychoactive substance users $[53,55]$. 
During the sampling, four young PSUs were purposefully selected and enrolled as seeds from each of the 12 informal settlements, resulting in a total of 48 seeds. To ensure that the selected seeds were young psychoactive substance users, we sought guidance from peer educators, staff of non-governmental organisations working on HIV and psychoactive substance programs and the local leaders. This increased the chances of selecting seeds with a large social network. We ensured seed diversity by ensuring geographical representativeness, gender, and age group. Selecting diverse seeds was aimed at improving the chances of reaching equilibrium. Equilibrium was established when there was no significant variation in the key study variables per informal settlements i.e., age group, gender, and informal settlement.

\section{Data collection and study variables}

Data were collected using an interviewer-administered structured questionnaire developed after a critical review of literature [56-59]. The questionnaire captured information on socio-demographic characteristics such as sex, age (in years), marital status, highest educational attainment, length of stay in a particular informal settlement, average individual monthly income, history of psychoactive substance use, sexual expectancies and inhibitions. The main outcome variables included multiple sexual partnerships, condom use and having sex under the influence of psychoactive substances. Multiple sexual partnerships were defined as having more than one sexual partner in the last 30 days [42]. Condom use was categorised as consistent and inconsistent. A respondent was considered a consistent user if he/she used condoms each time he/she had sexual intercourse with a nonspousal partner.

The main predictors in this study were sexual expectancies and inhibitions accrued from the use of psychoactive substances. Sexual expectancies were defined as perceptions of positive outcomes accrued from the use of psychoactive substances on an individual's sexual behaviour [60]. In this study, the sexual expectancies included improved sexual pleasure or euphoria, and performance, and boosting one's courage or confidence to approach a sexual partner. Inhibitions were defined as behaviours that go against one's conventional or natural sexual practices [61]. Such behaviours included finding it difficult to use condoms, forgetting to use a condom, a higher likelihood of engaging in sexual intercourse, finding it difficult to decline sexual advance, and finding one's self-wanting sex while under the influence of psychoactive substances.

The questionnaire (Additional file 1) was uploaded on the Kobo Collect application installed on android phones and tablets and interviews were conducted by well-trained data collectors. In preparation for actual data collection, the structured questionnaire (Additional file 1) was pretested among 20 young PSUs in a similar setting in Wakiso district and the feedback obtained during pretesting was used to refine the questionnaire.

\section{Statistical analyses}

All analyses were done using Stata 14 (StataCorp, Texas, USA). We summarised categorical data using frequencies and proportions. For numerical data, we used the mean and standard deviation to provide summary statistics. We compared the substance use related perceptions on sexual expectancies and inhibitions among males and females using chi-square statistics. To establish the relationship between sexual expectancies and inhibitions, and each of the high-risk sexual behaviours, we employed robust Poisson regression with a robust error variance. We fitted three separate models in order to establish the relationship between the independent variables (sexual expectancies and inhibitions) and each of the outcome variables i.e., engaging in multiple sexual partnerships in the last 30 days, having sex while under the influence of psychoactive substances, and condom use in the last 30 days. We used prevalence ratios (PRs) as more conservative measures of association than odds ratios since the prevalence of the outcomes was greater than $10 \%$ [62]. Stepwise backward regression was used, and a cut off $p$-value of less than 0.2 was set for variables eligible to be included in the multivariable model [63]. We adjusted for known confounders such as age, sex, and level of education. A $p$-value $<0.05$ was considered statistically significant.

\section{Results}

\section{Characteristics of the respondents}

A total of 744 young PSUs was studied. The mean age of the respondents was 21.5 years $(\mathrm{SD} \pm 2.1)$. About $76.6 \%$ of the respondents were aged $20-24$ years; $78.0 \%$ were males; and $85.3 \%$ did not live with their parents or guardians. More than three quarters, $78.2 \%$ of the respondents were single while the rest were married. Regarding the level of education, more than half, $58.2 \%$ had attained post primary education while the remainder had only attained primary education or less. About $74.3 \%$ of the respondents had used alcohol in the last 30 days while more than half, $51.9 \%$ had used marijuana. (Table 1).

\section{Frequency of psychoactive substance use}

About $40.1 \%$ of alcohol consumers used it at least 5 times a week; $63.9 \%$ of marijuana users used it at least 5 times a week; $45.6 \%$ of khat users used it at least 5 times a week while $42.3 \%$ of oral tobacco users used it at least 5 times a week. (Fig. 1). 
Table 1 Characteristics of young psychoactive substance users in the informal settlements of Kampala, Uganda

\begin{tabular}{|c|c|c|c|}
\hline Variable & Attribute & Frequency $(n=744)$ & Percentage (\%) \\
\hline \multirow[t]{2}{*}{ Age category } & $18-19$ & 174 & 23.4 \\
\hline & $20-24$ & 570 & 76.6 \\
\hline \multirow[t]{2}{*}{ Sex } & Male & 580 & 78.0 \\
\hline & Female & 164 & 22.0 \\
\hline \multirow[t]{5}{*}{ Religion } & Catholic & 291 & 39.1 \\
\hline & Anglican & 126 & 16.9 \\
\hline & Muslim & 222 & 29.8 \\
\hline & Born again/ Pentecostal & 80 & 10.8 \\
\hline & Other religion & 25 & 3.4 \\
\hline \multirow[t]{3}{*}{ Duration of staying in area (in years) } & $0-5$ & 264 & 35.5 \\
\hline & $6-10$ & 145 & 19.5 \\
\hline & Greater than 10 & 335 & 45.0 \\
\hline \multirow[t]{2}{*}{ Still staying with parents } & Yes & 109 & 14.7 \\
\hline & No & 635 & 85.3 \\
\hline \multirow[t]{3}{*}{ Average monthly income (Exchange rate: 1 USD = UGX 3755). } & $0-250,000$ & 477 & 64.1 \\
\hline & $250,001-500,000$ & 204 & 27.4 \\
\hline & Above 500,000 & 63 & 8.5 \\
\hline \multicolumn{4}{|l|}{ History of psychoactive substance use } \\
\hline \multirow[t]{2}{*}{ Used alcohol in the last 30 days } & Yes & 553 & 74.3 \\
\hline & No & 191 & 25.7 \\
\hline \multirow[t]{2}{*}{ Used marijuana in the last 30 days } & Yes & 386 & 51.9 \\
\hline & No & 358 & 48.1 \\
\hline \multirow[t]{2}{*}{ Used khat in the last 30 days } & Yes & 409 & 55.0 \\
\hline & No & 335 & 45.0 \\
\hline \multirow[t]{2}{*}{ Used heroin in the last 30 days } & Yes & 14 & 4.0 \\
\hline & No & 730 & 96.0 \\
\hline \multirow[t]{2}{*}{ Used oral tobacco in the last 30 days } & Yes & 67 & 9.0 \\
\hline & No & 677 & 91.0 \\
\hline
\end{tabular}

USD United Staes Dollar, UGX Uganda Shillings

\section{Sexual behaviours}

The median age at sex debut was 16.0 years $(\mathrm{IQR}=14$, 17 ), with a median number of sexual partners in the last 12 months at $3(\mathrm{IQR}=1,9)$. The median age at sex debut for males was 15.0 years $(\mathrm{IQR}=14,17)$ while that of females was 16 years $(\mathrm{IQR}=14,17)$. Nearly a quarter, $23.6 \%$ of respondents admitted ever intentionally intoxicating someone with psychoactive substances with the aim of luring them into sex. About $46.2 \%$ (43.8\% of males and $54.8 \%$ of females) of respondents or their partners used a psychoactive substance before the last sexual intercourse. Among those who used psychoactive substances before sex, $55.6 \%$ (27.8\% of males and $18.3 \%$ of females) mentioned that they alone had used the substances; in $39.2 \%$ ( $15 \%$ of males and $29.3 \%$ of females) both the respondent and the partner used the substances; in $5.2 \%$ ( $1 \%$ of males and $7.3 \%$ of females) only their sexual partner used the substances. Over half, $55.5 \%$ (27.4\% of males and $19.5 \%$ of females) of the respondents who used the psychoactive substances before sex reported being intoxicated during the most recent sexual intercourse, $36.1 \%$ (13.4\% of males and $28 \%$ of females) indicated that they and their partner were intoxicated during the last sexual intercourse and 5.5\% (1.4\% of males and $6.7 \%$ of females) said only their partner was intoxicated. Only $2.9 \%$ ( $1.5 \%$ of males and $0.6 \%$ of females) of respondents reported that none of them was intoxicated before the last sexual intercourse. About $36.5 \%$ of the 744 respondents had ever had sex with a commercial sex worker or sex client. About $36.8 \%$ of the males in the current study had ever had sex with a commercial sex worker while $35.4 \%$ of the females had ever had sex with a sex client. Out of the 744 respondents in our study, $32.5 \%$ had ever had sex with a commercial 


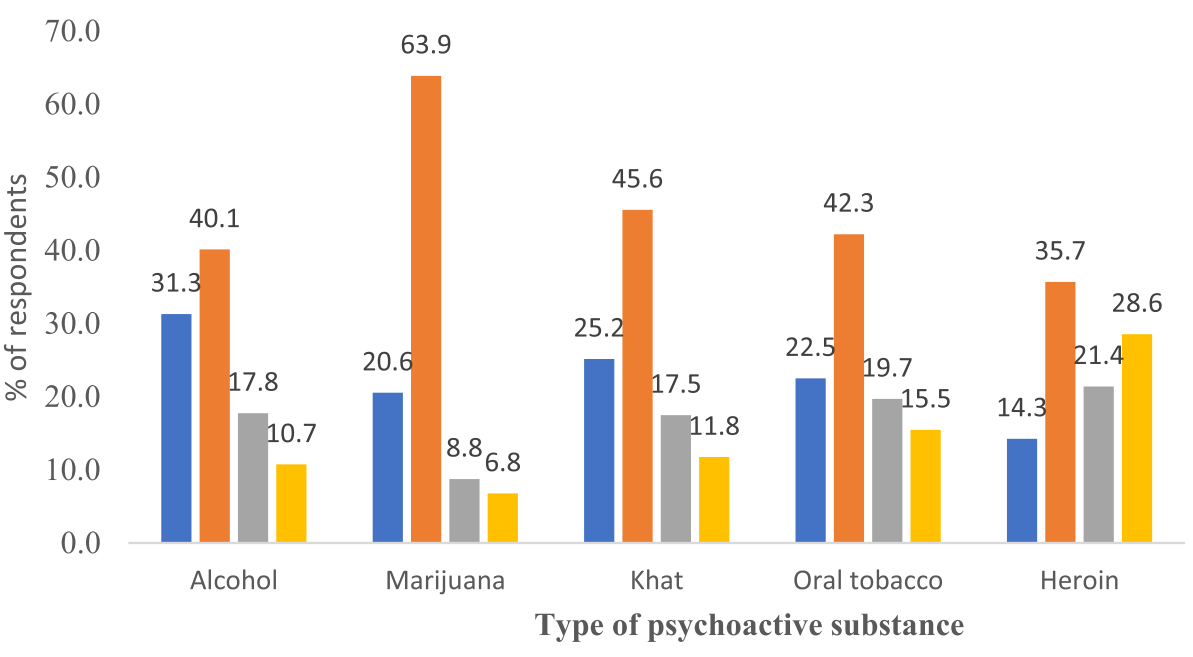

$\square$ 2-3 times a week $\square$ Atleast 5 times a week $\square 4$ times a week $\square$ Less than one a month

Fig. 1 Frequency of psychoactive substance use in the last 30 days

sex worker or client while intoxicated. About $41.5 \%$ of the females and $30 \%$ of the males had ever had sex with a sex client or commercial sex worker while intoxicated.

\section{Sexual expectancies and inhibitions}

Over $45 \%$ of the respondents believed that psychoactive substance use improves sexual performance, $43.3 \%$ believed that sex is more pleasurable when under the influence of psychoactive substances, while more than half (53.1\%) believed that using psychoactive substances gives courage or confidence to approach a partner for sex (Table 2).

\section{Association between sexual expectancies and inhibitions and high-risk sexual behaviours}

Results in Tables 3 and 4 show that respondents who endorsed that they were likely to engage in sex when under the influence of psychoactive substances had a $48 \%$ higher likelihood of engaging in multiple sexual relationships in the last 30 days compared to those who did not think so (PR 1.48, 95\% CI: 1.15-1.90). Respondents who indicated that it is difficult to refuse sex when under the influence of psychoactive substances had a $28 \%$ higher likelihood of engaging in multiple sexual relationships in the last 30 days compared to those who did not think so (PR 1.28, 95\% CI: 1.06-1.55) (Table 3). Believing that there is a higher likelihood of forgetting to use a condom while under the influence of psychoactive substances was positively associated with inconsistent condom use in the last 30 days (PR 1.26, 95\% CI: 1.091.45) (Table 4).

The beliefs that psychoactive substance use improves sexual performance (PR 1.14, 95\% CI: 1.01-1.30) or increases sexual urge (PR 1.20, 95\% CI: 1.04-1.40) were associated with a higher likelihood of having sex while under the influence of psychoactive substances in the last 30 days. The feeling that using psychoactive substances gives courage or confidence to approach a partner increased the likelihood of having sex while under the influence of psychoactive substances in the last 30 days by $21 \%$ (PR 1.21, 95\% CI: 1.05-1.39). Lastly, respondents who indicated finding themselves wanting to have sex when intoxicated had a $22 \%$ higher likelihood of having sex under the influence of psychoactive substances in the last 30 days compared to those who thought otherwise (PR 1.22, 95\% CI: 1.03-1.43) (Table 5).

\section{Discussion}

This is the first study to establish associations between sexual expectancies and inhibitions and high-risk sexual behaviours among young PSUs in the informal settlements of Kampala. Young PSUs in this study on average had an early sexual debut (15.2 years). The median age at sex debut was 15.0 years for females and 16.0 for females. These findings imply that young people using psychoactive substances, engage in early sexual intercourse compared to the national median age in the general population of 17.6 years for females and 18.0 years for males [64]. The differences in age at sex debut observed between females and males could be due to cultural norms, especially those encouraging more freedom and sexual experiences for boys than for girls $[65,66]$. Cultural socialization has been reported to influence the sexual behaviours of boys and girls [67]. In Uganda boys have more autonomy and less parental restrictions compared to girls, which gives them a leeway to engage in sexual intercourse even at an early age $[67,68]$. 
Table 2 Sexual expectancies and inhibitions among young psychoactive substance users in the informal settlements of Kampala, Uganda

\begin{tabular}{|c|c|c|c|c|c|}
\hline Variable & Attribute & $\begin{array}{l}\text { Overall } \\
(n=744)(\%)\end{array}$ & $\begin{array}{l}\text { Males } \\
\text { n (\%) }\end{array}$ & $\begin{array}{l}\text { Females } \\
\text { n (\%) }\end{array}$ & $p$-value \\
\hline \multirow[t]{2}{*}{ Psychoactive substance use improves sexual performance } & Yes & $339(45.6)$ & $262(45.2)$ & $77(46.9)$ & \\
\hline & No & $405(54.4)$ & $318(54.8)$ & $87(53.1)$ & 0.686 \\
\hline \multirow{2}{*}{$\begin{array}{l}\text { Sex is more pleasurable when under the influence of } \\
\text { psychoactive substances }\end{array}$} & Yes & $322(43.3)$ & $237(40.9)$ & $85(51.8)$ & \\
\hline & No & $422(56.7)$ & $343(59.1)$ & 79 (48.2) & $0.012^{*}$ \\
\hline \multirow{2}{*}{$\begin{array}{l}\text { Being under the influence of psychoactive substances make } \\
\text { it difficult for you to use condoms }\end{array}$} & Yes & $220(29.6)$ & $241(40.0)$ & $51(30.9)$ & \\
\hline & No & $524(70.4)$ & $362(60.0)$ & $114(69.1)$ & $0.034^{*}$ \\
\hline \multirow{2}{*}{$\begin{array}{l}\text { Being under the influence of psychoactive substances make } \\
\text { you forget to use a condom }\end{array}$} & Yes & $205(27.6)$ & $163(28.1)$ & $42(25.6)$ & \\
\hline & No & $539(72.4)$ & $417(71.9)$ & $122(74.4)$ & 0.528 \\
\hline \multirow{2}{*}{$\begin{array}{l}\text { Likely to engage in sex when under the influence of } \\
\text { psychoactive substances }\end{array}$} & Yes & $333(44.8)$ & $254(43.8)$ & $79(48.2)$ & \\
\hline & No & $411(55.2)$ & $326(56.2)$ & $85(51.8)$ & 0.320 \\
\hline \multirow{2}{*}{$\begin{array}{l}\text { Likely to find it difficult to refuse sex when under the } \\
\text { influence of alcohol or substances }\end{array}$} & Yes & $274(36.8)$ & $217(37.4)$ & $57(34.8)$ & \\
\hline & No & $470(63.2)$ & $363(62.6)$ & $107(65.2)$ & 0.533 \\
\hline \multirow{2}{*}{$\begin{array}{l}\text { Agreed that using psychoactive substances gives courage or } \\
\text { confidence to approach a partner for sex }\end{array}$} & Yes & $395(53.1)$ & $311(53.6)$ & $84(51.2)$ & \\
\hline & No & $349(46.9)$ & $269(46.4)$ & $80(48.8)$ & 0.586 \\
\hline \multirow[t]{2}{*}{ Find yourself wanting to have sex when using psychoactive drugs } & Yes & $352(47.3)$ & $270(46.5)$ & $82(50.0)$ & \\
\hline & No & $392(52.7)$ & $310(53.5)$ & $82(50.0)$ & 0.435 \\
\hline
\end{tabular}

Our study revealed significant differences in the proportion of males and females who felt that being under the influence of psychoactive substances made it difficult for them to use condoms. A higher proportion of males found it difficult to use condoms, compared to females. This could be due to the varying effects of psychoactive substances on sexual behaviour. Some psychoactive substances may deprive male users, the ability to wear a condom while others may think that sexual intercourse is more pleasurable without condoms.

There is also evidence that some psychoactive substances could deprive male users of the ability to sustain an erection, hence difficulties in putting on a condom [69]. In addition, Calysn, et al. [70] in their study reported that men often pointed out the negative effects of condom use on sexual experience. Young PSUs in their study reported not feeling good or natural, condoms not fitting well, change in orgasm, interruption of the sexual mood, and interference with feelings close to one's partner. A significantly higher proportion of females felt that sex was more pleasurable when under the influence of psychoactive substances. Although psychoactive substances have varying effects, it is believed that substances such as alcohol increase the sexual libido of women, and consequently pleasure [71, 72].

Nearly a quarter of the young PSUs in this study had ever made someone else intoxicated with psychoactive substances in order to have sex with them while nearly half of the young PSUs or their partners used a psychoactive substance before their last the sexual intercourse.
This is because a considerable proportion of the young PSUs expect that the use of psychoactive substances would improve sexual performance, give courage or confidence to approaching a partner for sex, and make sexual intercourse more pleasurable as evidenced by the study findings. Similar findings have been reported in other studies [60, 73, 74]. Getting someone intoxicated would make it easier for the partner to engage in sexual activity against their consent, mainly due to impaired cognition and decision making $[75,76]$. Using psychoactive substance prior to the last sexual intercourse was thought to improve their confidence to approach sexual partners. The use of these substances has been reported to increase aggression among users [77, 78]. These expectancies are likely to have lured some respondents into intoxicating their partners with psychoactive substances or even using psychoactive substances during their last sexual intercourse.

Respondents who felt that they were likely to engage in sex under the influence of psychoactive substances were more likely to engage in multiple sexual relationships compared to those who did not think so. Users of psychoactive substances are significantly more likely to have sexual intercourse compared to non-users [79]. Similarly, an increase in the sexual urge or libido, which often characterises psychoactive substance use, may have been an important driver for young people who find it difficult to refuse sex while under the influence of psychoactive substances for engaging in multiple sexual relationships. Having multiple sexual partners in Kampala's 
Table 3 Association between sexual expectancies and inhibitions, and multiple sexual partnerships among young psychoactive substance users in the informal settlements of Kampala, Uganda

\begin{tabular}{|c|c|c|c|c|c|c|c|}
\hline \multirow[t]{2}{*}{ Variable } & \multirow[t]{2}{*}{$\begin{array}{l}\text { Freq } \\
(n)\end{array}$} & \multicolumn{2}{|c|}{$\begin{array}{l}\text { Engaged in multiple sexual } \\
\text { relationships in the last } 30 \text { days }\end{array}$} & \multirow[t]{2}{*}{$\begin{array}{l}\text { Unadjusted } \\
\text { PR }(95 \% \mathrm{Cl})\end{array}$} & \multirow[t]{2}{*}{$\begin{array}{l}p- \\
\text { value }\end{array}$} & \multirow[t]{2}{*}{$\begin{array}{l}\text { Adjusted } \\
\text { PR }(95 \% \mathrm{Cl})\end{array}$} & \multirow[t]{2}{*}{$\begin{array}{l}p \text { - } \\
\text { value }\end{array}$} \\
\hline & & Yes & No & & & & \\
\hline \multicolumn{8}{|l|}{ Age category (years) } \\
\hline 18-19 & 174 & $73(24.2)$ & $101(22.9)$ & 1.0 & & 1.0 & \\
\hline $20-24$ & 570 & $229(75.8)$ & $341(77.1)$ & $0.95(0.78-1.17)$ & 0.674 & $0.89(0.73-1.07)$ & 0.228 \\
\hline \multicolumn{8}{|l|}{ Sex of the respondent } \\
\hline Male & 580 & $220(72.8)$ & $360(81.4)$ & 1.0 & & 1.0 & \\
\hline Female & 164 & $82(27.2)$ & $82(18.6)$ & $1.31(1.09-1.58)$ & 0.003 & $1.31(1.10-1.56)$ & $0.003^{*}$ \\
\hline \multicolumn{8}{|l|}{ Level of education } \\
\hline Primary and below & 310 & $137(45.4)$ & $173(39.1)$ & 1.0 & & 1.0 & \\
\hline Above primary & 434 & $165(54.6)$ & $216(60.9)$ & $0.86(0.72-1.02)$ & 0.089 & $0.98(0.83-1.16)$ & 0.903 \\
\hline \multicolumn{8}{|c|}{ Psychoactive substance use improves sexual performance } \\
\hline No & 405 & $128(42.4)$ & $277(62.7)$ & 1.0 & & 1.0 & \\
\hline Yes & 339 & $174(57.6)$ & $165(37.3)$ & $1.62(1.36-1.93)$ & $<0.001$ & $1.13(0.92-1.38)$ & 0.225 \\
\hline \multicolumn{8}{|c|}{ Psychoactive substance use makes sex more pleasurable } \\
\hline No & 422 & $135(44.7)$ & $287(64.9)$ & 1.0 & & 1.0 & \\
\hline Yes & 322 & $167(55.3)$ & $155(35.1)$ & $1.62(1.36-1.93)$ & $<0.001$ & $0.99(0.81-1.21)$ & 0.975 \\
\hline \multicolumn{8}{|c|}{ Psychoactive substance use makes it difficult to use condoms } \\
\hline Yes & 220 & $112(37.1)$ & $108(24.4)$ & 1 & & 1.0 & \\
\hline No & 524 & $190(62.9)$ & $334(75.6)$ & $1.40(1.18-1.66)$ & $<0.001$ & $0.85(0.70-1.04)$ & 0.132 \\
\hline \multicolumn{8}{|c|}{ Psychoactive substance use increases likelihood of forgetting to use a condom } \\
\hline No & 539 & $193(63.9)$ & $346(78.3)$ & 1 & & 1 & \\
\hline Yes & 205 & $109(63.1)$ & $96(21.7)$ & $1.48(1.25-1.76)$ & $<0.001$ & $0.86(0.71-1.06)$ & 0.172 \\
\hline \multicolumn{8}{|c|}{ Psychoactive substance use increases likelihood of engaging in sex } \\
\hline No & 411 & $111(36.8)$ & $300(67.9)$ & 1.0 & & 1.0 & \\
\hline Yes & 333 & $191(63.2)$ & $142(32.1)$ & $2.12(1.76-2.55)$ & $<0.001$ & $1.48(1.15-1.90)$ & $0.002^{*}$ \\
\hline \multicolumn{8}{|c|}{ Psychoactive substance use makes it difficult to refuse sex } \\
\hline No & 470 & $153(50.7)$ & $317(71.7)$ & 1.0 & & 1.0 & \\
\hline Yes & 274 & $149(49.3)$ & $125(28.3)$ & $1.67(1.41-1.97)$ & $<0.001$ & $1.28(1.06-1.55)$ & $0.008^{*}$ \\
\hline \multicolumn{8}{|c|}{ Psychoactive substance use gives courage/confidence to approach a partner for sex } \\
\hline No & 349 & $103(34.1)$ & $246(55.7)$ & 1.0 & & 1.0 & \\
\hline Yes & 395 & $199(65.9)$ & $196(44.3)$ & $1.70(1.41-2.06)$ & $<0.001$ & $1.16(0.93-1.45)$ & 0.171 \\
\hline \multicolumn{8}{|c|}{ Psychoactive substance use increases likelihood of wanting sex } \\
\hline No & 392 & $107(37.4)$ & $285(64.5)$ & 1.0 & & 1.0 & \\
\hline Yes & 352 & $195(64.6)$ & $157(35.5)$ & $2.02(1.68-2.44)$ & $<0.001$ & $1.24(0.96-1.61)$ & 0.093 \\
\hline
\end{tabular}

Cl Confidence interval, $P R$ Prevalence Ratio

informal settlements, a setting that already has a high prevalence of sex work and HIV among young people [46, 80] and the general population [81], is likely to escalate the transmission of sexually transmitted infections (STIs), including HIV/AIDS.

Respondents in our study, who felt they were likely to forget to use a condom, while under the influence of psychoactive substances, did not consistently use condoms. This is not surprising since psychoactive substances impair judgment and cognition [82]. Once under the influence of psychoactive substances, young people often fail to make the correct decisions or choices, including condom use. Our findings emphasize the need for risk reduction and other sexual and reproductive health interventions among this high-risk group.

This study also indicates that sexual expectancies such as improved sexual performance, confidence or courage, 
Table 4 Association between sexual expectancies and inhibitions, and condom use among young psychoactive substance users in the informal settlements of Kampala, Uganda

\begin{tabular}{|c|c|c|c|c|c|c|c|}
\hline \multirow[t]{2}{*}{ Variable } & \multirow{2}{*}{$\begin{array}{l}\text { Freq } \\
\text { (n) }\end{array}$} & \multicolumn{2}{|c|}{ Condom use in the last 30 days } & \multirow{2}{*}{$\begin{array}{l}\text { Unadjusted } \\
\text { PR }(95 \% \mathrm{Cl})\end{array}$} & \multirow{2}{*}{$\begin{array}{l}p- \\
\text { value }\end{array}$} & \multirow{2}{*}{$\begin{array}{l}\text { Adjusted } \\
\text { PR }(95 \% \mathrm{Cl})\end{array}$} & \multirow{2}{*}{$\begin{array}{l}p \text { - } \\
\text { value }\end{array}$} \\
\hline & & Consistent & Inconsistent & & & & \\
\hline \multicolumn{8}{|l|}{ Age category (years) } \\
\hline $18-19$ & 174 & $76(27.3)$ & $98(21.0)$ & 1.0 & & 1.0 & \\
\hline $20-24$ & 570 & $202(72.3)$ & $368(79.0)$ & $1.14(0.99-1.32)$ & 0.064 & $1.12(0.97-1.29)$ & 0.107 \\
\hline \multicolumn{8}{|l|}{ Sex of the respondent } \\
\hline Male & 580 & $223(80.2)$ & $357(76.6)$ & 1.0 & & 1.0 & \\
\hline Female & 164 & $55(19.8)$ & $109(23.4)$ & $1.07(0.95-1.22)$ & 0.234 & $1.09(0.95-1.23)$ & 0.185 \\
\hline \multicolumn{8}{|l|}{ Level of education } \\
\hline Primary and below & 310 & $115(41.4)$ & $195(41.8)$ & 1.0 & & 1.0 & \\
\hline Above primary & 434 & $163(58.6)$ & $271(58.2)$ & $0.99(0.88-1.11)$ & 0.898 & $1.05(0.93-1.17)$ & 0.387 \\
\hline
\end{tabular}

Psychoactive substance use improves sexual performance

$\begin{array}{llllll}\text { No } & 405 & 157(56.5) & 248(53.2) & 1.0 & \\ \text { Yes } & 339 & 121(43.5) & 218(46.8) & 1.05(0.93-1.17) & 0.387\end{array}$

Psychoactive substance use makes sex more pleasurable

\begin{tabular}{|c|c|c|c|c|c|c|c|}
\hline Yes & 322 & $106(38.1)$ & $216(46.4)$ & 1.0 & & 1.0 & \\
\hline No & 422 & $172(61.9)$ & $250(53.6)$ & $1.13(1.04-1.26)$ & 0.027 & $1.00(0.88-1.14)$ & 0.931 \\
\hline
\end{tabular}

Psychoactive substance use makes it difficult to use condoms

\begin{tabular}{|c|c|c|c|c|c|c|}
\hline Yes & 220 & 55 (19.8) & 165 (35.4) & 1.0 & & 1.0 \\
\hline No & 524 & $223(80.2)$ & $301(64.6)$ & $1.30(1.17-1.45)$ & $<0.001$ & $0.96(0.83-1.10)$ \\
\hline
\end{tabular}

Psychoactive substance use increases likelihood of forgetting to use a condom

\begin{tabular}{|c|c|c|c|c|c|c|}
\hline No & 539 & $230(82.7)$ & $309(66.3)$ & 1.0 & & 1.0 \\
\hline Yes & 205 & $48(17.3)$ & $157(33.7)$ & $1.33(1.20-1.48)$ & $<0.001$ & $1.26(1.09-1.45)$ \\
\hline
\end{tabular}

Psychoactive substance use increases likelihood of engaging in sex

\begin{tabular}{|c|c|c|c|c|c|c|c|}
\hline No & 411 & $175(62.9)$ & $236(50.6)$ & 1.0 & & 1.0 & \\
\hline Yes & 333 & $103(37.1)$ & $230(49.4)$ & $1.20(1.07-1.34)$ & 0.001 & $1.07(0.92-1.25)$ & 0.355 \\
\hline \multicolumn{8}{|c|}{ sychoactive substance use makes it difficult to refuse sex } \\
\hline No & 470 & $193(69.4)$ & $277(59.4)$ & 1.0 & & 1.0 & \\
\hline Yes & 274 & 85 (30.6) & 189 (40.6) & $1.17(1.04-1.30)$ & 0.005 & $1.01(0.89-1.15)$ & 0.840 \\
\hline
\end{tabular}

Psychoactive substance use gives courage/confidence to approach a partner for sex

\begin{tabular}{|c|c|c|c|c|c|}
\hline No & 349 & $130(46.8)$ & $219(47.0)$ & 1.0 & \\
\hline Yes & 395 & $148(53.2)$ & $247(53.0)$ & $0.99(0.89-1.11)$ & 0.951 \\
\hline
\end{tabular}

Psychoactive substance use increases likelihood of wanting sex

\begin{tabular}{llllllll} 
No & 392 & $164(59.0)$ & $228(48.9)$ & 1.0 & 1.0 & \\
Yes & 352 & $114(41.0)$ & $238(51.1)$ & $1.16(1.04-1.29)$ & $\mathbf{0 . 0 0 8}$ & $0.99(0.85-1.16)$ & 0.942 \\
\hline
\end{tabular}

Cl Confidence interval, PR Prevalence Ratio

and increased sexual desire increased the likelihood of engaging in sex under the influence of psychoactive substances. Young PSUs often resort to the use of these substances as a way of sustaining erections and bettering sexual performance [60]. A significant proportion of young girls and women in the informal settlements of Kampala engage in commercial sex and use of psychoactive substances among female sex workers has been reported in several studies [80, 83, 84].
Young PSUs in this study were less sexually inhibited. Those who endorsed that they were likely to engage in sex when under the influence of psychoactive substances were more likely to have sex while intoxicated compared to those who did not think so. This too, could be attributed to the effects of psychoactive substance use of sexual urge, desire, and anticipated expectancies such as better sexual performance. There is evidence for instance that alcohol makes women more sensuous and more 
Table 5 Association between sexual expectancies and inhibitions, and ever had sex while under the influence of psychoactive substances among young psychoactive substance users in the informal settlements of Kampala, Uganda

\begin{tabular}{|c|c|c|c|c|c|c|c|}
\hline \multirow[t]{2}{*}{ Variable } & \multirow[t]{2}{*}{$\begin{array}{l}\text { Freq } \\
(\mathrm{n})\end{array}$} & \multicolumn{2}{|c|}{$\begin{array}{l}\text { Had sex under the influence } \\
\text { of drugs in the last } 30 \text { days }\end{array}$} & \multirow{2}{*}{$\begin{array}{l}\text { Unadjusted } \\
\text { PR }(95 \% \mathrm{Cl})\end{array}$} & \multirow[t]{2}{*}{$\begin{array}{l}p- \\
\text { value }\end{array}$} & \multirow{2}{*}{$\begin{array}{l}\text { Adjusted } \\
\text { PR }(95 \% \mathrm{Cl})\end{array}$} & \multirow[t]{2}{*}{$p$-value } \\
\hline & & Yes & No & & & & \\
\hline \multicolumn{8}{|l|}{ Age category (years) } \\
\hline $18-19$ & 174 & $82(18.1)$ & $92(31.7)$ & 1.0 & & 1.0 & \\
\hline $20-24$ & 570 & $372(81.9)$ & $198(68.3)$ & $1.38(1.17-1.68)$ & $<0.001$ & $1.32(1.13-1.54)$ & $<0.001$ \\
\hline \multicolumn{8}{|l|}{ Sex of respondent } \\
\hline Male & 580 & $337(74.2)$ & $243(83.8)$ & 1.0 & & 1.0 & \\
\hline Female & 164 & $117(25.8)$ & $47(16.2)$ & $1.22(1.08-1.38)$ & 0.001 & $1.19(1.05-1.34)$ & $0.004^{*}$ \\
\hline \multicolumn{8}{|l|}{ Level of education } \\
\hline Primary and below & 310 & $209(46.0)$ & $101(34.8)$ & 1.0 & & 1.0 & \\
\hline Above primary & 434 & $245(54.0)$ & $189(65.2)$ & $0.83(0.74-0.93)$ & 0.002 & $0.94(0.84-0.15)$ & 0.288 \\
\hline \multicolumn{8}{|c|}{ Psychoactive substance use improves sexual performance } \\
\hline No & 405 & $200(44.1)$ & $205(70.7)$ & 1.0 & & 1.0 & \\
\hline Yes & 339 & $254(55.9)$ & $85(29.3)$ & $1.51(1.35-1.70)$ & $<0.001$ & $1.14(1.01-1.30)$ & $0.029^{*}$ \\
\hline \multicolumn{8}{|c|}{ Psychoactive substance use increases likelihood of forgetting to use a condom } \\
\hline No & 539 & $294(64.8)$ & $245(84.5)$ & 1.0 & & 1.0 & \\
\hline Yes & 205 & $160(35.2)$ & $45(15.5)$ & $1.43(1.28-1.59)$ & $<0.001$ & $1.05(0.93-1.18)$ & 0.360 \\
\hline \multicolumn{8}{|c|}{ Psychoactive substance use increases likelihood of engaging in sex } \\
\hline No & 411 & $192(42.3)$ & $219(75.5)$ & 1.0 & & 1.0 & \\
\hline Yes & 333 & $262(57.7)$ & $71(24.5)$ & $1.68(1.49-1.89)$ & $<0.001$ & $1.20(1.04-1.40)$ & $0.013^{*}$ \\
\hline \multicolumn{8}{|c|}{ Psychoactive substance use makes it difficult to refuse sex } \\
\hline No & 470 & $254(55.9)$ & $216(74.5)$ & 1.0 & & 1.0 & \\
\hline Yes & 274 & $200(44.1)$ & $74(25.5)$ & $1.35(1.20-1.50)$ & $<0.001$ & $1.05(0.93-1.18)$ & 0.371 \\
\hline \multicolumn{8}{|c|}{ Psychoactive substance use gives courage/confidence to approach a partner for sex } \\
\hline No & 349 & $162(35.7)$ & $187(64.5)$ & 1.0 & & 1.0 & \\
\hline Yes & 395 & $292(64.3)$ & $103(35.5)$ & $1.59(1.40-1.80)$ & $<0.001$ & $1.21(1.05-1.39)$ & $0.006^{*}$ \\
\hline \multicolumn{8}{|c|}{ Psychoactive substance use increases likelihood of wanting sex } \\
\hline No & 392 & $178(39.2)$ & $214(73.8)$ & 1.0 & & 1.0 & \\
\hline Yes & 352 & $276(60.8)$ & $76(26.2)$ & $1.72(1.52-1.95)$ & $<0.001$ & $1.22(1.03-1.43)$ & $0.016^{*}$ \\
\hline
\end{tabular}

Cl Confidence interval, PR Prevalence Ratio

romantic [85]. It could be this feeling that propels young PSUs to further engage in sexual intercourse when intoxicated. Our findings should be an eye opener to policy makers and those who engage in HIV/AIDS programming on the immediate risk posed by young PSU as far as the transmission of HIV is concerned. It is therefore important to expand the HIV prevention services to integrate preventing and mitigating the effects of psychoactive substances and to stem the transition to injecting drug use, which is more complex to manage [36].

\section{Strengths and limitations of the study}

To the best of our knowledge, this is the first study to establish an association between sexual expectancies and inhibitions and high-risk sexual behaviours among young PSUs in informal settlements. However, this was a cross- sectional design and thus, it was not possible to draw causal inferences between the influence of psychoactive substances and high-risk sexual behaviours. Sexual expectancies and inhibitions could be affected depending on the dose of the psychoactive substance used; therefore, these findings cannot be generalised to all PSUs with varied doses. Substance use and sexual behaviours were self-reported, which could be subject to both recall and social desirability biases. Besides, this study did not apply sample weights, making it prone to unequal selection probability $[55,86]$.

\section{Conclusion}

This study has established the association between sexual expectancies and inhibitions with high-risk sexual behaviours i.e., inconsistent condom use, engagement in multiple sexual partnerships, and having sex while under 
the influence of psychoactive substances in informal settings where other complications like poverty are already exposing young people to STIs and HIV risk. Psychoactive substance use expectancies associated with high-risk sexual behaviours included the belief that psychoactive substances improve sexual performance and give courage or confidence to approach a sexual partner. Psychoactive substance use inhibitions associated with high-risk sexual behaviours included an increased likelihood of engaging in sexual intercourse, difficulties in refusing to engage in sexual intercourse, and forgetting to use condoms while intoxicated. The campaign against high-risk sexual behaviours should explicitly include a message that the use of psychoactive substances promotes high-risk sexual behaviours. Further research could focus on understanding how expectancies and inhibitions accrued from independent psychoactive substances influence high-risk sexual behaviours, and/or how the dose of psychoactive substances influences sexual expectancies and high-risk sexual behaviours.

\section{Abbreviations}

AIDS: Acquired immunodeficiency syndrome; HIV: Human immunodeficiency virus; PR: Prevalence ratio; PSUs: Psychoactive substance users;

RDS: Respondent Driven Sampling; STI: Sexually transmitted infection

\section{Supplementary Information}

The online version contains supplementary material available at https://doi. org/10.1186/s12889-021-11536-8.

Additional file 1. Data collection tool.

\section{Acknowledgements}

We would like to thank the study participants for sparing their time to respond to the data collection tool. We are grateful to the leadership of the Directorate of Public Health and Environment, Kampala Capital City Authority (KCCA), and the leadership of the respective informal settlements for their cooperation and support during data collection. Special thanks also go to study coordinators (Patience Oputan, Aisha Nalugya) and research assistants (Andrew David Mugisha, Nyakabwa Job, Joanna Nakiggala, Kiiza Ignatius, Namulindwa Gloria, Soigi Christine and Bambuza Olivia) for their invaluable effort during the implementation of the study.

\section{Authors' contributions}

TS, SPSK and MT conceptualised the study, participated in data collection, analysis and drafting the manuscript. JBI, RKM, STW, EB, CKN, JNB, and RKW participated in the analysis, and drafting of the manuscript. All authors read and approved this manuscript before submission to this journal.

\section{Funding}

This study was not funded by any entity.

\section{Availability of data and materials}

The datasets analysed during the current study are available from the corresponding author upon reasonable request.

\section{Declarations}

\section{Ethics approval and consent to participate}

We obtained ethical approval for the study from the Makerere University School of Public Health Higher Degrees, Research and Ethics Committee (HDREC). Administrative clearance to conduct this study was obtained from Kampala Capital City Authority (KCCA) and the local authorities in the selected informal settlements. Participation in the study was entirely voluntary and informed written consent was obtained. Individual privacy was ensured by treating the data as confidential and conducting the interviews from secluded places. Data were not collected on the names, place of residence or any other information that would reveal the identity of the respondents. This reduced the risk of respondents being identified by law enforcers like police.

Consent for publication

Not applicable.

\section{Competing interests}

The authors declare that they have no competing interests.

\section{Author details}

${ }^{1}$ Department of Disease Control and Environmental Health, Makerere University School of Public Health, Kampala, Uganda. ${ }^{2}$ Department of Community Health and Behavioural Sciences, Makerere University School of Public Health, Kampala, Uganda. ${ }^{3}$ School of Pharmacy, University of Waterloo, Waterloo, Canada. ${ }^{4}$ Departement of Epidemiology and Global Health, Umeå University, 90187 Umeå, Sweden. ${ }^{5}$ Department of Health Policy, Planning and Management, Makerere University School of Public Health, Kampala, Uganda.

Received: 5 May 2020 Accepted: 23 July 2021

Published online: 04 August 2021

\section{References}

1. UNODC. World Drug Report 2020. Vienna: United Nations Office on Drugs and Crime; 2020. Available from: https://wdr.unodc.org/wdr2020/

2. Abbo C, Okello ES, Muhwezi W, Akello G, Ovuga E. Alcohol, Substance Use and Psychosocial Competence of Adolescents in Selected Secondary Schools in Uganda: A Cross Sectional Survey. Int Neuropsychiatr Dis J. 2016; 7(2):25387.

3. Swahn MH, Culbreth R, Salazar LF, Kasirye R, Seeley J. Prevalence of HIV and associated risks of sex work among youth in the slums of Kampala. AIDS Res Treat. 2016;2016:5360180

4. Ghulam R, Verma K, Sharma P, Razdan M, Razdan RA. Drug abuse in slum population. Indian J Psychiatry. 2016;58(1):83-6. https://doi.org/10.4103/001 9-5545.174390.

5. Girish N, Kavita R, Gururaj G, Benegal V. Alcohol use and implications for public health: patterns of use in four communities. Indian J Community Med. 2010;35(2):238-44. https://doi.org/10.4103/0970-0218.66875.

6. Sarangi L, Acharya HP, Panigrahi OP. Substance abuse among adolescents in urban slums of Sambalpur. Indian J Community Med. 2008;33(4):265-7. https://doi.org/10.4103/0970-0218.43236.

7. Bardhan T, Saikia A, Baruah R. Factors influencing substance use among adolescent slum dwellers of Guwahati City, Assam. J Mahatma Gandhi Inst Med Sci. 2018;23(1):25-9. https://doi.org/10.4103/jmgims.jmgims_21_16.

8. Chawla N, Sarkar S. Defining "high-risk sexual behavior" in the context of substance use. J Psychosexual Health. 2019;1 (1):26-31. https://doi.org/10.11 77/2631831818822015

9. Paquette R, Tanton C, Burns F, Prah P, Shahmanesh M, Field N, et al. Illicit drug use and its association with key sexual risk behaviours and outcomes: Findings from Britain's third National Survey of Sexual Attitudes and Lifestyles (Natsal-3). PLoS One. 2017;12(5):e0177922-e.

10. Saw YM, Saw TN, Chan N, Cho SM, Jimba M. Gender-specific differences in high-risk sexual behaviors among methamphetamine users in MyanmarChina border city, Muse, Myanmar: who is at risk? BMC Public Health. 2018; 18(1):209.

11. Paquette R, Tanton C, Burns F, Prah P, Shahmanesh M, Field N, et al. Illicit drug use and its association with key sexual risk behaviours and outcomes: findings from Britain's third National Survey of sexual attitudes and lifestyles (Natsal-3). PLoS One. 2017;12(5):e0177922. https://doi.org/10.1371/journal. pone. 0177922

12. Madise NJ, Ziraba AK, Inungu J, Khamadi SA, Ezeh A, Zulu EM, et al. Are slum dwellers at heightened risk of HIV infection than other urban residents? Evidence from population-based HIV prevalence surveys in Kenya. Health Place. 2012;18(5):1144-52. https://doi.org/10.1016/.healthplace.2012. 04.003. 
13. Bayless SJ, Harvey AJ. Testing alcohol myopia theory: examining the effects of alcohol intoxication on simultaneous central and peripheral attention. Perception. 2017;46(1):90-9. https://doi.org/10.1177/0301006616672221.

14. Steele CM, Josephs RA. Alcohol myopia: its prized and dangerous effects. Am Psychol. 1990;45(8):921-33. https://doi.org/10.1037/0003-066X.45.8.921.

15. Wells BE, Golub SA, Parsons JT. An integrated theoretical approach to substance use and risky sexual behavior among men who have sex with men. AIDS Behav. 2011;15(3):509-20. https://doi.org/10.1007/s10461-0109767-z.

16. Dumbili EW. Gendered sexual uses of alcohol and associated risks: a qualitative study of Nigerian University students. BMC Public Health. 2016; 16(1):474. https://doi.org/10.1186/s12889-016-3163-1.

17. Maisto SA, Simons JS. Research on the Effects of Alcohol and Sexual Arousal on Sexual Risk in Men who have Sex with Men: Implications for HIV Prevention Interventions. AIDS Behav. 2016;20(Suppl 1(Suppl 1)):S158-S72.

18. Maisto SA, Palfai T, Vanable PA, Heath J, Woolf-King SE. The effects of alcohol and sexual arousal on determinants of sexual risk in men who have sex with men. Arch Sex Behav. 2012;41(4):971-86. https://doi.org/10.1007/s1 0508-011-9846-x

19. Weir BW, Latkin CA. Alcohol, intercourse, and condom use among women recently involved in the criminal justice system: findings from integrated global-frequency and event-level methods. AIDS Behav. 2015;19(6):1048-60. https://doi.org/10.1007/s10461-014-0857-1.

20. Massa AA, Subramani OS, Eckhardt Cl, Parrott DJ. Problematic alcohol use and acute intoxication predict anger-related attentional biases: a test of the alcohol myopia theory. Psychol Addict Behav. 2019;33(2):139-43. https://doi. org/10.1037/adb0000426.

21. McKirnan DJ, Vanable PA, Ostrow DG, Hope B. Expectancies of sexual "escape" and sexual risk among drug-and alcohol-involved gay and bisexual men. J Subst Abus. 2001;13(1-2):137-54. https://doi.org/10.1016/S0899-32 89(01)00063-3

22. Nemeroff CJ, Hoyt MA, Huebner DM, Proescholdbell RJ. The cognitive escape scale: measuring HIV-related thought avoidance. AIDS Behav. 2008; 12(2):305-20. https://doi.org/10.1007/s10461-007-9345-1.

23. Tang J, Wu S, Miao D. Experimental test of escape theory: accessibility to implicit suicidal mind. Suicide Life Threat Behav. 2013;43(4):347-55. https:// doi.org/10.1111/sltb.12021.

24. Dermen KH, Cooper ML, Agocha VB. Sex-related alcohol expectancies as moderators of the relationship between alcohol use and risky sex in adolescents. J Stud Alcohol. 1998;59(1):71-7. https://doi.org/10.15288/jsa.1 998.59.71.

25. White HR, Fleming CB, Catalano RF, Bailey JA. Prospective associations among alcohol use-related sexual enhancement expectancies, sex after alcohol use, and casual sex. Psychol Addict Behav. 2009;23(4):702-7. https:// doi.org/10.1037/a0016630.

26. Manyaapelo T, Van den Borne B, Ruiter RA, Sifunda S, Reddy P. Effectiveness of a health Behavioural intervention aimed at reduction of risky sexual Behaviours among young men in the KwaZulu-Natal Province, South Africa. Int J Environ Res Public Health. 2019;16(11):1938. https://doi.org/10.3390/ ijerph16111938.

27. Odimegwu C, Somefun OD. Ethnicity, gender and risky sexual behaviou among Nigerian youth: an alternative explanation. Reprod Health. 2017; 14(1):16. https://doi.org/10.1186/s12978-017-0284-7.

28. Darteh EKM, Dickson KS, Amu H. Understanding the socio-demographic factors surrounding young peoples' risky sexual behaviour in Ghana and Kenya. J Community Health. 2020;45(1):141-7. https://doi.org/10.1007/s1 0900-019-00726-6.

29. Degenhardt L, Charlson F, Ferrari A, Santomauro D, Erskine H, MantillaHerrara A, Whiteford H, Leung J, Naghavi M, Griswold M, Rehm J. The global burden of disease attributable to alcohol and drug use in 195 countries and territories, 1990-2016: a systematic analysis for the Global Burden of Disease Study 2016. The Lancet Psychiatry. 2018;5(12):987-1012.

30. Obot IS. Substance use among students and out-of-school youth in an urban area of Nigeria: WHO Geneva; 2005

31. Watt MH, Meade CS, Kimani S, MacFarlane JC, Choi KW, Skinner D, et al. The impact of methamphetamine ("tik") on a peri-urban community in Cape Town, South Africa. Int J Drug Policy. 2014;25(2):219-25. https://doi.org/10.1 016/j.drugpo.2013.10.007.

32. Magidson JF, Dietrich J, Otwombe KN, Sikkema KJ, Katz IT, Gray GE. Psychosocial correlates of alcohol and other substance use among lowincome adolescents in peri-urban Johannesburg, South Africa: a focus on gender differences. J Health Psychol. 2017;22(11):1415-25. https://doi.org/1 $0.1177 / 1359105316628739$

33. Cheng Y, Sherman SG, Srirat N, Vongchak T, Kawichai S, Jittiwutikarn J, et al. Risk factors associated with injection initiation among drug users in Northern Thailand. Harm Reduct J. 2006;3:10.

34. Werb D, Bluthenthal RN, Kolla G, Strike C, Kral AH, Uusküla A, et al Preventing injection drug use initiation: state of the evidence and opportunities for the future. J Urban Health. 2018;95(1):91-8. https://doi. org/10.1007/s11524-017-0192-8

35. Roy É, Haley N, Leclerc P, Boudreau J-F, Boivin J-F. Risk factors for initiation into drug injection among adolescent street youth. Drugs. 2007;14(5):389-99.

36. Haber PS, Demirkol A, Lange K, Murnion B. Management of injecting drug users admitted to hospital. Lancet. 2009;374(9697):1284-93. https://doi.org/1 0.1016/S0140-6736(09)61036-9.

37. Skalski LM, Gunn RL, Caswell A, Maisto S, Metrik J. Sex-related marijuana expectancies as predictors of sexual risk behavior following smoked marijuana challenge. Exp Clin Psychopharmacol. 2017;25(5):402-11. https:// doi.org/10.1037/pha0000138.

38. Metrik J, Rohsenow DJ, Monti PM, McGeary J, Cook TAR, de Wit H, et al. Effectiveness of a marijuana expectancy manipulation: piloting the balanced-placebo design for marijuana. Exp Clin Psychopharmacol. 2009; 17(4):217-25. https://doi.org/10.1037/a0016502.

39. Ssekamatte T, Isunju JB, Balugaba BE, Nakirya D, Osuret J, Mguni P, et al. Opportunities and barriers to effective operation and maintenance of public toilets in informal settlements: perspectives from toilet operators in Kampala. Int J Environ Health Res. 2019;29(4):359-70. https://doi.org/10.1 080/09603123.2018.1544610.

40. Kasirye R. Interface of substance abuse and child prostitution: intervening in the lives of slum and street children in Kampala-Uganda. Citeseer; 2005.

41. Kasirye R. Sexual risks, Substance abuse and Protective factors among, Kampala Street and slum children; 2018.

42. Ssekamatte T, Tetui M, Kibira SPS, Isunju JB, Mugambe RK, Nabiwemba $E_{\text {, et }}$ al. Multiple sexual partnerships and associated factors among young psychoactive-substance-users in informal settlements in Kampala, Uganda. PLoS One. 2020;15(10):e0239323. https://doi.org/10.1371/journal. pone.0239323.

43. Swahn M, Haberlen M, Palmier JB. Alcohol and drug use and other high-risk behaviors among youth in the slums of Kampala, Uganda: perceptions and contexts obtained through focus groups. Int J Alcohol Drug Res. 2014;3(4): 289-95. https://doi.org/10.7895/ijadr.v3i4.171.

44. Huchzermeyer M, Karam A. Informal settlements: a perpetual challenge?: Juta and company Itd; 2006

45. Swahn MH, Culbreth RE, Staton CA, Self-Brown SR, Kasirye R. Alcoholrelated physical abuse of children in the slums of Kampala, Uganda. Int J Environ Res Public Health. 2017;14(10):1124. https://doi.org/10.3390/ ijerph14101124.

46. Swahn MH, Culbreth R, Salazar LF, Tumwesigye NM, Kasirye R. Psychosocial correlates of self-reported HIV among youth in the slums of Kampala. BMC Public Health. 2019;19(1):1176.

47. Swahn MH, Palmier JB, Kasirye R. Alcohol Exposures, Alcohol Marketing, and Their Associations with Problem Drinking and Drunkenness among Youth Living in the Slums of Kampala, Uganda. ISRN Public Health. 2013;2013:948675.

48. UBOS. The national population and housing census 2014-main report. Kampala: Uganda Bureau of Statistics; 2016.

49. WHO. Global status report on alcohol and health 2018: World Health Organization; 2019. [cited 2021 20th July ]. Available from: https://www. who.int/publications/i/item/9789241565639.

50. Aldridge J, Charles V. Researching the intoxicated: informed consent implications for alcohol and drug research. Drug Alcohol Depend. 2008; 93(3):191-6. https://doi.org/10.1016/j.drugalcdep.2007.09.001.

51. Kish L. Survey sampling. New York: Wiley; 1965.

52. Alimohamadi $Y$, Sepandi M. Considering the design effect in cluster sampling. J Cardiovasc Thorac Res. 2019;11(1):78.

53. WHO, CDC, UNAIDS, FHI. Biobehavioral survey guidelines for populations at risk for HIV. Geneva: World Health Organization; 2017.

54. Ssekamatte T, Tetui M, Kibira SP, Isunju JB, Mugambe RK, Nabiwemba E, et al. Multiple sexual partnerships and associated factors among young psychoactive-substance-users in informal settlements in Kampala, Uganda. PLoS One. 2020;15(10):e0239323. https://doi.org/10.1371/journal. pone.0239323. 
55. Selvaraj V, Boopathi K, Paranjape R, Mehendale S. A single weighting approach to analyze respondent-driven sampling data. Indian J Med Res. 2016;144(3):447-59. https://doi.org/10.4103/0971-5916.198665.

56. Ragsdale K, Bersamin MM, Schwartz SJ, Zamboanga BL, Kerrick MR, Grube JW. Development of sexual expectancies among adolescents: contributions by parents, peers and the media. J Sex Res. 2014;51(5):551-60. https://doi. org/10.1080/00224499.2012.753025.

57. Holloway IW, Traube DE, Schrager SM, Levine B, Alicea S, Watson JL, et al. The effects of sexual expectancies on early sexualized behavior among urban minority youth. J Soc Soc Work Res. 2012;3(1):1-12. https://doi.org/10. 5243/jsswr.2012.1.

58. Steward WT, Satyanarayana VA, Heylen E, Srikrishnan AK, Vasudevan CK, Krishnan G, et al. Alcohol use, expectancies and HIV-related sexual risk: a cross-sectional survey of male migrant workers in South India. AIDS Care. 2018;30(5):656-62. https://doi.org/10.1080/09540121.2017.1394964.

59. Florimbio AR, Brem MJ, Garner AR, Grigorian HL, Stuart GL. Alcohol-related sex expectancies explain the relation between alcohol use and sexting among college students. Comput Hum Behav. 2018;88:205-9. https://doi. org/10.1016/j.chb.2018.07.005.

60. Reesor L, Vaughan EM, Hernandez DC, Johnston CA. Addressing outcomes expectancies in behavior change. Am J Lifestyle Med. 2017;11(6):430-2. https://doi.org/10.1177/1559827617722504.

61. Rodriguez-Nieto G, Sack AT, Dewitte M, Emmerling F, Schuhmann T. Putting out the blaze: the neural mechanisms underlying sexual inhibition. PLoS One. 2019;14(1):e0208809. https://doi.org/10.1371/journal.pone.0208809.

62. Tamhane AR, Westfall AO, Burkholder GA, Cutter GR. Prevalence odds ratio versus prevalence ratio: choice comes with consequences. Stat Med. 2016; 35(30):5730-5. https://doi.org/10.1002/sim.7059.

63. Bursac Z, Gauss CH, Williams DK, Hosmer DW. Purposeful selection of variables in logistic regression. Source Code Biol Med. 2008;3(1):17. https:// doi.org/10.1186/1751-0473-3-17.

64. UBOS ICF. Uganda demographic and health survey 2016. Kampala and Rockville: UBOS and ICF; 2018.

65. Wellings K, Collumbien M, Slaymaker E, Singh S, Hodges Z, Patel D, et al. Sexual behaviour in context: a global perspective. Lancet (London, England). 2006;368(9548):1706-28.

66. Bantebya GK, Muhanguzi FK, Watson C. Adolescent girls and gender justice: understanding key capability domains in Uganda: Country Report London: ODI; 2013.

67. Beyeza-Kashesya J, Neema S, Ekstrom AM, Kaharuza F. "Not a Boy, Not a Child": A qualitative study on young people's views on childbearing in Uganda. African journal of reproductive health. 2010;14(1).

68. Ninsiima AB, Leye E, Michielsen K, Kemigisha E, Nyakato VN, Coene G. "Girls Have More Challenges; They Need to Be Locked Up": A Qualitative Study of Gender Norms and the Sexuality of Young Adolescents in Uganda. Int J Environ Res Public Health. 2018;15(2):193.

69. Bogart LM, Kral AH, Scott A, Anderson R, Flynn N, Gilbert ML, et al. Condom attitudes and behaviors among injection drug users participating in California syringe exchange programs. AIDS Behav. 2005;9(4):423-32. https:// doi.org/10.1007/s10461-005-9014-1.

70. Calsyn DA, Peavy M, Wells EA, Campbell ANC, Hatch-Maillette MA, Greenfield SF, et al. Differences between men and women in condom use, attitudes, and skills in substance abuse treatment seekers. Am J Addict. 2013;22(2):150-7. https://doi.org/10.1111/j.1521-0391.2013.00312.x.

71. Paone D, Cooper H, Alperen J, Shi Q, Jarlais DD. HIV risk behaviours of current sex workers attending syringe exchange: the experiences of women in five US cities. AIDS Care. 1999;11(3):269-80. https://doi.org/10.1080/0954 0129947910

72. Sharma V, Sarna A, Tun W, Saraswati LR, Thior I, Madan I, et al. Women and substance use: a qualitative study on sexual and reproductive health of women who use drugs in Delhi, India. BMJ Open. 2017;7(11):e018530. https://doi.org/10.1136/bmjopen-2017-018530.

73. Volkow ND, Wang G-J, Fowler JS, Telang F, Jayne M, Wong C. Stimulantinduced enhanced sexual desire as a potential contributing factor in HIV transmission. Am J Psychiatr. 2007;164(1):157-60. https://doi.org/10.1176/a jp.2007.164.1.157.

74. Harawa NT, Williams JK, Ramamurthi HC, Manago C, Avina S, Jones M. Sexual behavior, sexual identity, and substance abuse among low-income bisexual and non-gay-identifying African American men who have sex with men. Arch Sex Behav. 2008;37(5):748-62. https://doi.org/10.1007/s10508008-9361-x.
75. Anderson KG, Briggs KE. Self-regulation and decision making. In: The Oxford Handbook of Adolescent Substance Abuse, vol. 463; 2019.

76. Valyan A, Ekhtiari H, Smith R, Paulus MP. Decision-making deficits in substance use disorders: cognitive functions, assessment paradigms, and levels of evidence: Cognition and Addiction: Elsevier; 2020. p. 25-61.

77. Abbey A, Zawacki T, Buck PO, Clinton AM, McAuslan P. Alcohol and sexual assault. Alcohol Res Health. 2001;25(1):43-51.

78. Stappenbeck CA, Gulati NK, Davis KC. A prospective examination of Men's condom use resistance: event-level associations with sexual aggression, alcohol consumption, and trait anger. J Sex Res. 2019;56(8):947-56. https:// doi.org/10.1080/00224499.2019.1620162.

79. Abate A, Tareke M, Tirfie M, Semachew A, Amare D, Ayalew E. Chewing khat and risky sexual behavior among residents of Bahir Dar City administration, Northwest Ethiopia. Ann General Psychiatry. 2018;17(1):26. https://doi.org/1 0.1186/s12991-018-0194-2.

80. Swahn MH, Culbreth R, Salazar LF, Kasirye R, Seeley J. Prevalence of HIV and associated risks of sex work among youth in the slums of Kampala. AIDS Res Treat. 2016;2016:1-8. https://doi.org/10.1155/2016/5360180.

81. Ministry of Health. Uganda Population-Based HIV Impact Assessment (UPHIA) 2016-2017. Ministry of Health. Kampala: MOH Uganda; 2017.

82. Costache E, Stoian MG. New drugs-possible effects that may LEAD0 to road accidents/NOILE DROGURI-POSIBILE EFECTE CE pot conduce la ACCIDENTE RUTIERE. Romanian J Forensic Sci. 2014;15(96):1829.

83. Li Q, Li X, Stanton B. Alcohol use among female sex workers and male clients: an integrative review of global literature. Alcohol Alcohol. 2010;45(2): 188-99. https://doi.org/10.1093/alcalc/agp095.

84. Decker MR, Park JN, Allen ST, Silberzahn B, Footer K, Huettner S, et al. Inconsistent condom use among female sex workers: partner-specific influences of substance use, violence, and condom coercion. AIDS Behav. 2020;24(3):762-74. https://doi.org/10.1007/s10461-019-02569-7.

85. Smith G, Toadvine J, Kennedy A. Women's perceptions of alcohol-related sexual disinhibition: personality and sexually-related alcohol expectancies. Int J Sex Health. 2009;21(2):119-31. https://doi.org/10.1080/19317610902 973241.

86. Rudolph AE, Fuller CM, Latkin C. The importance of measuring and accounting for potential biases in respondent-driven samples. AIDS Behav 2013;17(6):2244-52. https://doi.org/10.1007/s10461-013-0451-y.

\section{Publisher's Note}

Springer Nature remains neutral with regard to jurisdictional claims in published maps and institutional affiliations.

Ready to submit your research? Choose BMC and benefit from:

- fast, convenient online submission

- thorough peer review by experienced researchers in your field

- rapid publication on acceptance

- support for research data, including large and complex data types

- gold Open Access which fosters wider collaboration and increased citations

- maximum visibility for your research: over $100 \mathrm{M}$ website views per year

At $\mathrm{BMC}$, research is always in progress.

Learn more biomedcentral.com/submissions 